1. Kang J, Shen W, Macdonald R. Why does fever trigger febrile seizures? $\mathrm{GABA}_{\mathrm{A}}$ receptor $\gamma 2$ subunit mutations associated with idiopathic generalized epilepsies have temperature-dependent trafficking deficiencies. J Neurosci 2006;26:2590-2597.

2. Rossetti A, Tosi C, Despland P, Staedler C. Post-ictal fever: a rare symptom of partial seizures. Eur J Neurol 2007;14:586-590.
El-Ad B, Neufeld M. Periodic febrile confusion as a presentation of complex status epilepticus. Acta Neurol Scand 1990;82:350-352.

4. Chan K. Epilepsy - another cause of intermittent fever with confusion. Postgrad Med J 1992;68:119-120.

5. Meo R, Bilo L, Striano S, Ruosi P, Estraneo A, Nocerino C. Transient global amnesia of epileptic origin accompanied by fever. Seizure 1995;4:311-317.

\title{
Hopkins verbal learning test-revised and brief visuospatial memory test-revised: preliminary normative data for the Brazilian population
}

\author{
Hopkins verbal learning test-revised e brief visuospatial memory test-revised: referencial \\ normativo preliminar para a população brasileira
}

\section{Eliane Correa Miotto', Kenia Repiso Campanholo², Melissa Machado Rodrigues², Valéria Trunkl Serrao², Mara C S de Lucia², Milberto Scaff}

\section{'Department of Neurology, Hospital das Clínicas, Universidade de São Paulo (USP), São Paulo SP, Brazil; \\ ${ }^{2}$ Psychology Division, Hospital das Clínicas, Universidade de São Paulo (USP), São Paulo SP, Brazil.}

Correspondence: Eliane Correa Miotto; Divisão de Neurologia Clínica; Departamento de Neurologia; Avenida Dr. Enéas de Carvalho Aguiar 255; 05403-900 São Paulo SP - Brasil; E-mail: ecmiotto@usp.br

Conflict of interest: There is no conflict of interest to declare.

Received 17 May 2012; Received in final form 28 May 2012; Accepted 06 June 2012

Memory functions are cognitive processes related to the ability to encode, store and retrieve information associated to the fronto-temporal neurocircuitry ${ }^{1}$. Episodic memory refers to the system that allows conscious recollection of personal events or episodes and their contexts (time and place) $)^{1}$. Clinical measures of episodic memory include immediate and delayed free recall and recognition of word lists and pictures. Amongst these measures, the Hopkins verbal learning test-revised ${ }^{2}$ (HVLT-R) and the brief visuospatial memory test-revised ${ }^{3}$ (BVMT-R) are used to assess verbal episodic memory and visuospatial episodic memory, respectively, both including immediate, delayed and recognition. Although they are adopted as measures of memory functions in clinical practice, there are no normative data for the Brazilian adult and elderly population. The aim of this study was to present preliminary normative data for the HVLT-R and BVMT-R in a sample of the Brazilian population.

\section{METHODS}

The study, carried out at Department of Neurology and Psychology Division, Central Institute, Hospital das Clínicas, Universidade de São Paulo, Medical School, included 1,108 adult and elderly participants (18 to 85 years old and 0 to 17 years of education) recruited from different states in Brazil (São Paulo, Minas Gerais, Rio de Janeiro, Paraná, Santa Catarina, Goiás, Bahia e Alagoas). Subjects with neurologic and psychiatric disorders were excluded after answering a semi-structured interview questionnaire. The inclusion criteria was (a) Mini-mental state examination score above the cutoff for cognitive impairment based on education ${ }^{4}$; (b) Independence on daily-life activities; and (c) Hospital anxiety and depression scale scores below the cutoff for anxiety and depression ${ }^{5}$. The HVLT-R and BVMT-R were administered according to the test manual instructions and, for both tests, Form I was used. For HVLT-R, participants were instructed to memorize a list of 12 words (nouns) drawn from 3 semantic categories (precious stones, animals and human dwellings). The test includes an immediate recall derived from three learning trials, a delayed recall trail (after 20-25 min) and a yes/no delayed recognition trial. For BVMT-R, six geometric visual designs were shown to the participants for 10 seconds and after that, they were asked to reproduce as many of the designs as possible in the same location. This test includes an immediate recall derived from the three learning trials, a delayed recall (25 minutes) and a recognition trial.

Descriptive analyses and non-parametric tests using SigmaStat 3.5 (Kruskal-Wallis, Mann Whitney and post-hoc test using Muller-Dunn) were performed in order to investigate the influence of age, education, and gender on test performance. Statistical significance was established at 0.05 . 
RESULTS

Participants' test performance is presented on Table. The results showed a significant influence of age (BVMT-R immediate: $\mathrm{H}=54.09$, $\mathrm{p}<0.001$; BVMT-R delayed: $\mathrm{H}=64.47, \mathrm{p}<0.001$; BVMT- $\mathrm{R}$ recognition: $\mathrm{H}=28.34$, $\mathrm{p}<0.001$; HVLT-R recognition: $\mathrm{H}=24.28, \mathrm{p}<0.001$ ) and years of education (BVMT-R immediate: $\mathrm{H}=206.29, \mathrm{p}<0.001$; BVMT-R delayed: $H=205.14$, $<<0.001$; BVMT- $\mathrm{R}$ recognition: $\mathrm{H}=70.13, \mathrm{p}<0.001$; HVLT- $\mathrm{R}$ immediate: $\mathrm{H}=286.85$, $\mathrm{p}<0,001$; HVLT-R delayed: $\mathrm{H}=248.48, \mathrm{p}<0.001$; HVLT-R recognition: $H=77.87, p<0.001)$ on subjects test results. ROC curve analyses showed no significant influence of gender on test performance ( $p>0.05)$.

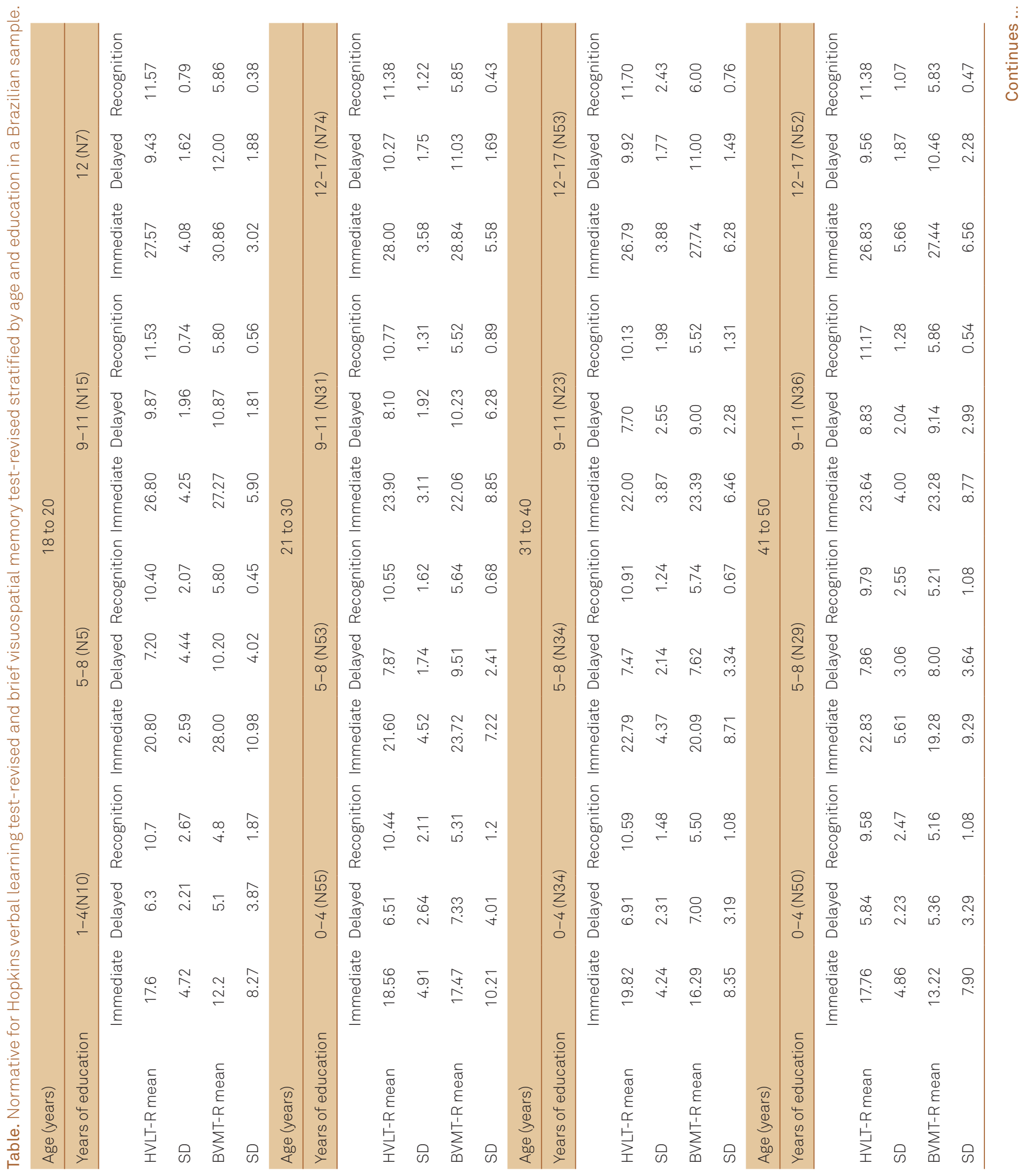




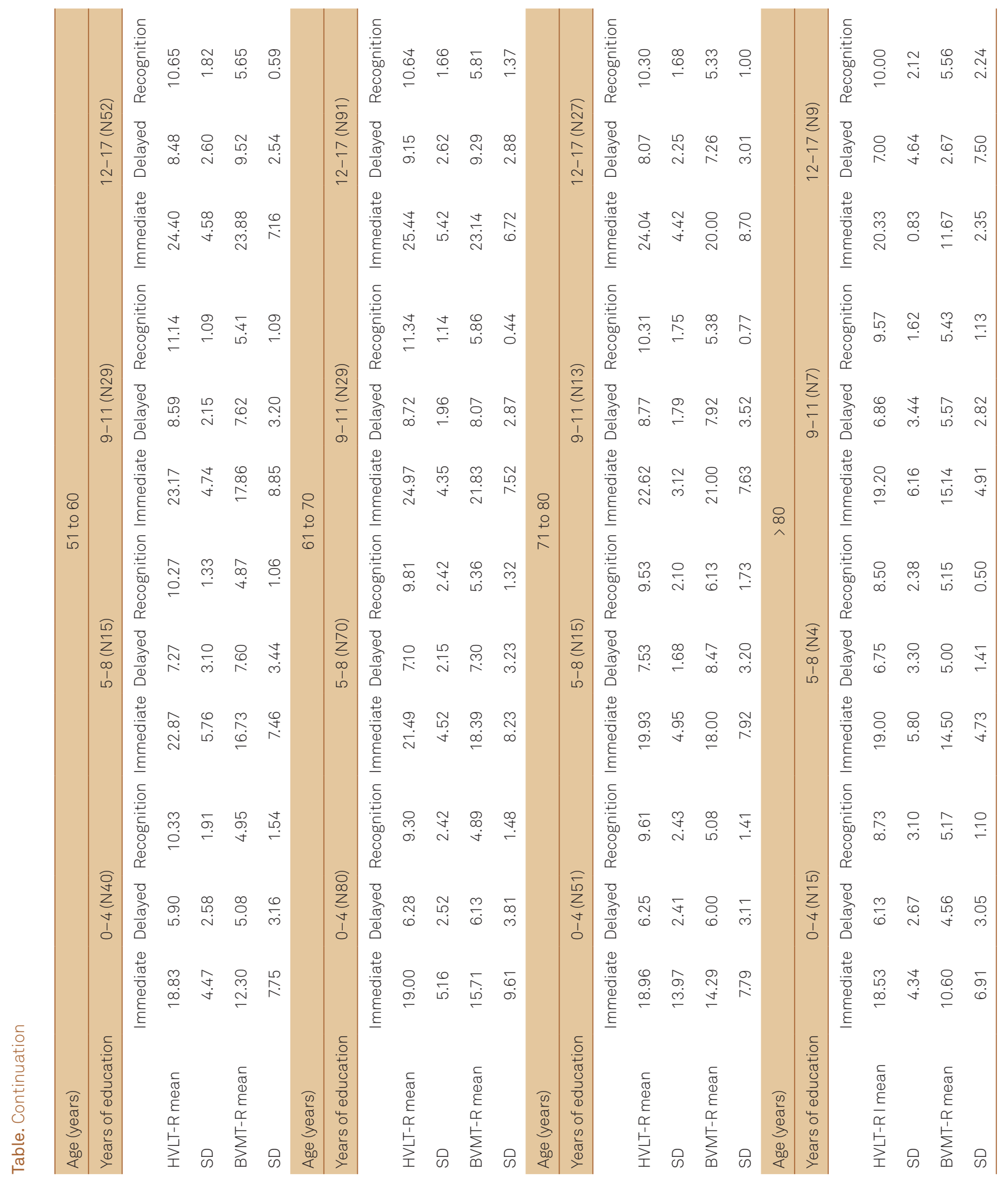

\section{DISCUSSION}

The HVLT-R and BVMT-R are neuropsychological tests validated for the assessment of verbal and visuospatial learning and episodic memory ${ }^{1}$. In the present, as well as, in the original data, there was a significant influence of age on both tests. In the current investigation, education also showed significant influence on the results possibly due to the different levels of education of the sample. In the majority of the studies, including the present one, gender had no influence on subjects' tests results. These findings demonstrate the importance of adequate normative data for memory assessment in clinical setting. They also present preliminary data for a sample of the Brazilian population, stratified according to age and education that can be useful in the learning and memory assessment of clinical conditions including mild cognitive disorders, dementia, traumatic brain injury, cerebral vascular accident and neuropsychiatry disorders. 
Tulving E. Concepts of human memory. In: Squire L, Lynch G, Weinberger NM, McGaugh JL (editors). Memory: organization and locus of change. New York: Oxford Univ. Press, 1991.

2. Brandt J, Benedict RHB. Hopkins verbal learning test - revised. Odessa: Psychological Assessment Resource, 2001.

3. Benedict RHB. Brief visuospatial memory test - revised. Odessa:
Psychological Assessment Resource, 1997

4. Brucki S, Nitrini R, Caramelli P, Bertolucci PHF, Okamoto $\mid H$. Sugestões para o uso do mini-exame do estado mental no Brasil. Ara Neuropsiquiatr 2003:61:777-781.

5. Zigmond AS, Snaith RP. The hospital anxiety and depression scale. Acta Psychiatr Scand 1983;67:361-370.

\title{
Reversible parkinsonism associated with neurocysticercosis
}

\author{
Parkinsonismo reversível associado com neurocisticercose \\ Plínio M. G. de Lima, Renato P. Munhoz, Hélio A. G. Teive
}

Movement Disorders Unit, Neurology Service, Internal Medicine Department, Hospital de Clínicas, Federal University of Paraná, Curitiba PR, Brazil.

Correspondence: Hélio A. G. Teive; Rua General Carneiro 1.103 / 102; 80060-150 Curitiba PR - Brasil; E-mail: hagteive@mps.com.br

Conflict of interest: There is no conflict of interest to declare.

Received 23 May 2012; Received in final form 04 June 2012; Accepted 11 June 2012

A 38-year-old female was assessed in a county hospital with a four-month history of severe throbbing morning headaches. Due to the syndromic diagnosis of intracranial hypertension, a brain magnetic resonance imaging (MRI) was performed showing evidence of supratentorial noncommunicating hydrocephalus because of an intraventricular cyst. The cyst was located at the level of the frontal horn of the right lateral ventricle, extending through the foramen of Monro to the third ventricle. Additionally, there were signs of edema in the midbrain periaqueductal region. The patient was treated with a ventriculoperitoneal (VP) shunt, and the symptoms of intracranial hypertension improved. A diagnosis of neurocysticercosis (NCC) was established after analysis of CSF, and positive antibodies reactions were detected. The patient was started on high-dose oral albendazole ( $3.2 \mathrm{~g}$ qd). After four days, additional signs were detected, including mutism, hypomimia, and sialorrhea, associated with severe parkinsonism (marked rigidity, bradykinesia, and resting upper limb tremor). A new brain MRI showed milder hydrocephalus. However, the intraventricular cyst and cerebral aqueduct edema and ependymitis remained unchanged (Figs 1 and 2).

At such point, she was referred to our Service of Neurology at the Hospital de Clínicas, Federal University of Paraná. On admission, neurological examination showed a severe Parkinsonian syndrome that also included marked postural instability, anarthria, and vertical ophthalmoparesis for upward gaze.

Our diagnosis was of Parkinsonism secondary to NCC. We believe that treatment with high-dose albendazole made the presentation worse by adding a reactive inflammatory response and by aggravating ependymitis and tissue damage.
Methylprednisolone pulse therapy was then started ( $1 \mathrm{~g}$ intravenous, daily, for five days). Symptomatic treatment also included levodopa/carbidopa (250/50 mg daily), with progressive improvement in Parkinsonism symptom. Finally, she then underwent endoscopic neurosurgery including monroplasty, removal of the cyst, pellucidoctomy, and third ventriculostomy. Neuropathological examination confirmed the diagnosis of NCC.

Eight months later, the patient was progressively withdrawn from dopaminergic treatment and remained asymptomatic, able to return to her routine activities.

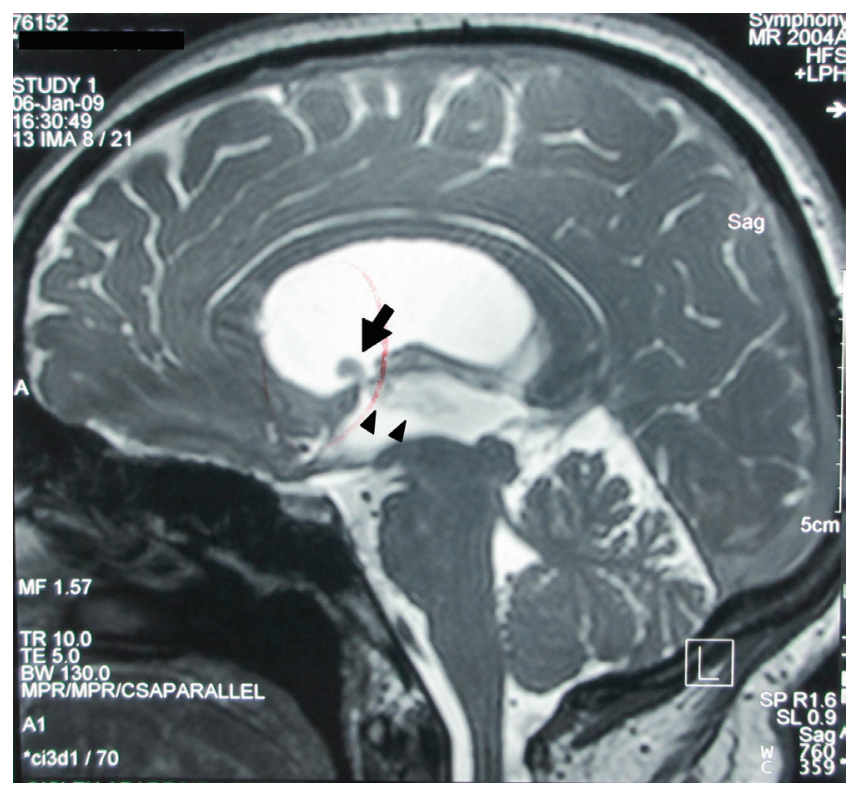

Fig 1. Brain magnetic resonance imaging sagittal T2-weighted image showed an intraventricular cyst (arrow) extending to the third ventricle (arrowheads). 